\title{
Stillbirth and perinatal care: Are professionals trained to address parents' needs?
}

\author{
Claudia Ravaldi, MD,MSc ${ }^{\mathrm{a}, \mathrm{b}}$, Miriam Levi, $\mathrm{MD}, \mathrm{PhD}^{\mathrm{c}}$, Elena Angeli, MPsy ${ }^{\mathrm{a}}$, \\ Gianpaolo Romeo, MMathStat ${ }^{c}$, Marco Biffino, MMathStat ${ }^{c}$, Roberto Bonaiuti, MEng ${ }^{\mathrm{d}}$, \\ Alfredo Vannacci, $\mathrm{MD}, \mathrm{PhD}^{\mathrm{a}, \mathrm{b}, \mathrm{d}, *}$ \\ ${ }^{a}$ CiaoLapo Onlus, Charity for Stillbirth and Perinatal Grief Support, Prato, Italy \\ b International Stillbirth Alliance, Bristol, UK \\ ${ }^{\mathrm{c}}$ CeRIMP-Regional Centre for Occupational Diseases and Injuries, Tuscany Region, Florence, Italy \\ ${ }^{\mathrm{d}}$ Department of Neurosciences, Psychology, Drug Research and Child Health (NeuroFarBa), University of Florence, Viale Pieraccini 6, 50139 Firenze, Italy
}

\section{A R T I C L E I N F O}

\section{Keywords:}

Stillbirth

Care providers

Midwives

Perinatal bereavement care

Guidelines

\begin{abstract}
A B S T R A C T
Objective: To assess current practices of health care providers (HCPs) caring for women experiencing a stillbirth and to explore their needs for training to better support bereaved families.

Design: Nationwide cross-sectional survey. The main outcome measures were the evaluation of HCPs cognition, emotions and behaviours with regard to the care of women with a stillbirth care, as well as their compliance with international guidelines.

Participants: $750 \mathrm{HCPs}$, in 11 Italian hospitals, were administered a multiple-choice questionnaire.

Findings: The response rate was $89.9 \%$; the majority $(94.1 \%)$ were female, with a mean age of $37.6(S D=10.4)$ years. Midwives were the most represented (72.8\%). Half of the respondents recommended immediate birth; only $55 \%$ routinely bathed and dressed stillborn babies for their parents to see, while $44.4 \%$ of HCPs immediately took the babies away without allowing parents to properly say goodbye to them. More than half felt inadequate and some even reported having failed to provide support to the family when caring for a woman with stillbirth in the past. The need for professional training courses was expressed by $90.2 \%$, and three-quarters had never previously attended a course on perinatal bereavement care. When answers by Italian HCPs are systematically evaluated with reference to international guidelines, the results were very poor with only $27.9 \%$ of respondents reported having created memories of the baby and less than $3 \%$ complied with all recommendations in the areas of respect for baby and parents, appropriate birth options, and aftercare.

Key conclusions: There is a substantial gap between the standards of care defined by international guidelines and the practices currently in place in Italy. Italian HCPs feel an urgent need to be offered professional training courses to better meet the needs of grieving families.

Implication for practice: Perinatal HCPs should be aware of their pivotal role in helping bereaved parents after stillbirth and perinatal loss, and seek appropriate training.
\end{abstract}

\section{Introduction}

Stillbirth is a traumatic event that can dramatically change the life of parents and families. The period after the loss of a stillborn baby has extensive consequences, mainly due to the negative effects of grief, anxiety, fear, and suffering. Negative psychological symptoms after a stillbirth have been reported in almost all parents, as well as in about 95\% of professionals involved (Heazell et al., 2016); perinatal loss, and stillbirth in particular, is in fact widely considered a highly stressful event by professionals (Nuzum et al., 2014).
Health care providers (HCPs) such as midwives, obstetricians, nurses and psychologists play, a pivotal role in the management of the event and in parents' care (Gold et al., 2007; Säflund et al., 2004) as shown by the large number of international guidelines. Although most guidelines are tailored for specific national health systems and often address local issues, they nevertheless share some key points for the care of women and families experiencing stillbirth. For example, most guidelines recommend that: HCPs should use simple language, showing a nonjudgmental sense of caring and personal involvement; enable parents to spend as much time as needed with their baby; facilitate the creation

\footnotetext{
* Corresponding author.

E-mail address: alfredo.vannacci@unifi.it (A. Vannacci).
} 
of mementos; provide information regarding post-mortem examination; make time for discussion with parents; respect their cultural and religious background and arrange follow-up meetings to discuss the results of the examination and to address unanswered questions (PSANZ, 2014; SANDS, 2016; Van Aerde, 2001).

The strong emotional impact on care providers can influence parents' decision-making process and impair their subsequent wellbeing by way of their attitudes at the time of diagnosis, birth, discharge and follow up, as well as their approach towards the baby (Sanchez, 2001). Even providing standard care, such as communicating news of a baby's death to the parents, assisting the birth of the baby, being present when parents meet the baby, can be perceived as extremely difficult tasks to accomplish, particularly in certain countries (Frøen et al., 2011). Stillbirth is amongst the most difficult experiences for medical consultants, who feel the burden of human response to bereaved parents, as well as the weight of responsibility, both at a professional and medical-legal level (Nuzum et al., 2014).

Women dealing with stillbirth are, by definition, highly stressed and, if the health care staff are not sufficiently attentive and professional, the distress linked to the event can be aggravated by inappropriate behaviours during pregnancy, labour and birth (Rådestad et al., 1998). However, parents who are properly assisted and supported from the moment of the diagnosis of the baby's death in-utero until discharge express less negative emotions during their mourning process (Ewton, 1993; Hutti, 2005). Being supported by properly trained professionals is extremely important (Ellis et al., 2016) since most parents affected by perinatal loss are likely to develop typical conditions of shock, grief, disbelief, and emotional anaesthesia (Kersting and Wagner, 2012; Ryninks et al., 2014), with relevant consequences also on subsequent pregnancies (Hutti et al., 2015; Wojcieszek et al., 2016). This is particularly true for women after stillbirth. During the shock phase, the memory process is enhanced: even if the mother may appear to be confused, almost everything occurring during this phase will be remembered in great detail afterwards, and traumatic memories may emerge long after the traumatic event (Pullen et al., 2012). The risk of inducing a 'secondary trauma' due to inappropriate clinical and psychological management during the acute phase should not be underestimated by professionals.

Some authors have recently proposed that women's experiences with stillbirth could be used as an indicator of quality of care processes, considering that quality maternity care incorporates not only clinical but also interpersonal and emotional aspects (Flenady et al., 2016). The approaches of parents, professionals and peers to stillbirth are very different among countries, in particular between those of high-income and low-income. Nevertheless, health care providers (HCP) in some highincome countries, such as Italy, are more likely to practise approaches used in low-income countries (Frøen et al., 2011). Several studies suggest that this may be due to a lack of specific training programs during pre-registration courses (Homer et al., 2016; Nuzum et al., 2014) and also to an absence of shared knowledge about stillbirth and care during perinatal loss (Frøen et al., 2016). Despite the efforts of parent-centred associations worldwide, stillbirth is still a neglected issue in many countries and it is often perceived as a taboo subject (Flenady et al., 2016; Heazell et al., 2016). As a consequence, many HCPs fail to receive appropriate training on the care of families experiencing stillbirth and many ignore widely available international guidelines on perinatal loss support, basing their behaviour mostly on cultural and/or religious beliefs (Frøen et al., 2011).

Thus, the aim of the present study was threefold:

- to investigate HCPs' opinions and behaviors regarding the care of women experiencing stillbirth;

- to address HCPs' compliance with international guidelines;

- to assess HCPs' perceived need for specific post-graduate training when perinatal death occurs.

\section{Methods}

Between 2009 and 2015, 750 HCPs routinely involved in perinatal care, working in 11 different obstetric and maternity hospital units in an equal number of Italian cities (namely Alessandria, Ancona, Florence, Gorizia, Milan, Novara, Padua, Pistoia, Pordenone, Treviso and Udine), distributed in six different regions, were administered a specifically developed 23-item multiple-choice questionnaire, using an approach called "Lucina". The study was authorized by all participating hospital authorities. All data were collected and analysed anonymously.

\section{Lucina questionnaire}

"For thou Eileithyia alone canst give relief to pain, which art attempts to ease, but tries in vain. Eileithyia, venerable power, who bringest relief in labour's dreadful hour"

\section{Orphic Hymn 2 to Prothyraea}

Lucina was the Roman counterpart of the Greek goddess Eileithyia, whose name means "she who comes to aid" or "relieve" from the Greek word 'eleluthyia'. In ancient Roman religion and myth, Lucina was the goddess of childbirth who safeguarded the lives of newborns and women in labour. The name Lucina, derived from the Latin word 'lux, lucis' (light), means "she who brings (children into the) light", and she was the most important of all deities who influenced every aspect of birth and child development.

The Lucina questionnaire was developed by the CiaoLapo Charity Organization for Stillbirth and Perinatal Loss Support in order to explore knowledge and beliefs of professionals on the most difficult aspects of midwifery practice, with particular focus on the care of women experiencing stillbirth and perinatal loss. The specific aim of the questionnaire was initially to investigate behaviours and practice of HCPs during both the acute phase of the loss and the grieving process. The questionnaire was administered in Italian and some methodological issues and preliminary results were published in Italian journals and presented in international congresses. Lucina is not a rating questionnaire but rather uses a structured interview. It was originally designed as an open-ended questionnaire and administered to a sample of $40 \mathrm{HCPs}$. An analysis of the initial data allowed for modification (2009, unpublished data) and into the present structured form ( 23 close-ended questions) used in the multicentre study reported here (2009-2015). An English translation of the questionnaire is provided as supplementary material to this paper.

\section{Guidelines}

Compliance with international guidelines was assessed by means of the CLASS checklist (CiaoLApo Stillbirth Support checklist). The CLASS checklist is a summary of best evidence from international guidelines, specifically developed to test HCPs knowledge of recommendations for stillbirth management and to address perception of assistance by parents of stillborn babies. The tool is available online in Italian (www.class.ciaolapo.it) and it is currently under validation (data not reported). In the CLASS checklist, recommendations are divided into sections loosely based on the guidelines from the Perinatal Society of Australia and New Zealand (PSANZ) (PSANZ, 2014), integrated with those of the Canadian Pediatric Society (Van Aerde, 2001), Health Services Executive Ireland (2016), and WHO-UNFPA-UNICEF (2007). The sections explored are as follows:

- Respect (R): respectful attitudes towards stillborn babies and their parents. The most important items evaluated are: naming the baby, bathing and dressing the baby, providing privacy, enabling partners to spend time together. Corresponding Lucina items: 11c, 11d, 11e, 11f, 14a, 14b, 14c, 15b, 15c, 15e. 
- Birth (B): approaches toward birth options. The most important items evaluated are: supporting parents to make appropriate decisions regarding birth, offering the option of returning home before birth, offering obstetric analgesia while avoiding sedation. Corresponding Lucina items: 12b, 12c, 14e, 18a, 18b, 18c.

- Mementoes (M): help parents create memories of the baby. The most important items evaluated are: taking pictures of the baby, supporting parents to see, hold, bathe and dress their baby, providing parents with mementos, such as a lock of hair, footprints, ID bracelet, etc. Corresponding Lucina items: 15a, 15d, 15f, 15g, 18e, 18f, 18g, $18 \mathrm{~h}$.

- Aftercare (A): provide appropriate care and support after the birth and the immediate postpartum period. The most important items evaluated are: informing mothers on physical and psychological consequences of perinatal loss, providing early psychological support, providing written information about support services, discussing implications for future pregnancies. Corresponding Lucina items: $18 \mathrm{i}$, $19,20,21,22$.

This paper reports Italian perinatal HCPs' beliefs and practises regarding supporting women and families who experience stillbirth using the Lucina questionnaire process. The paper also reports on compliance with recommendations from international guideline of regarding stillbirth care and support.

\section{Data collection}

The questionnaire was administered as hardcopies in 11 hospitals from 2009 to 2015, with the help of midwifery students (see acknowledgements) in the frame of their midwifery graduation dissertation work. All practising midwives, obstetricians, nurses, and psychologists of the ob/gyn wards were included in the study (750 participants in total). Participants recruited were sent a hardcopy of the questionnaire. No additional inclusion or exclusion criterion was applied.

\section{Statistical analysis}

Results related to the items exploring behaviours and emotions of HCPs, and their opinions regarding the need for professional training courses are reported here. Hardcopy questionnaires were transcribed by a professional data entry person who recorded them in a spreadsheet using Microsoft Excel 2010. After a data entry validation process on a random sample of $10 \%$ of records in the spreadsheet, data were imported into an R 3.1 workspace using the package 'xlsx' and a descriptive analysis was undertaken. Results are expressed as means and standard deviations for quantitative variables and as absolute and relative frequencies for nominal variables.

\section{Results}

Out of the 750 questionnaires distributed, 674 were completed and returned giving a response rate of $89.9 \%$. The majority of HCPs $(94.1 \%)$ were female, and mean age was $37.6(\mathrm{SD}=10.4)$ years. Midwives were the most represented $(72.8 \%), 14.7 \%$ were physicians, $6.4 \%$ nurses, and a minority $(6.1 \%)$ were other professional figures, including psychologists and trainees. Participants had, on average, 13.7 years of work experience $(S D=10.4)$. Further demographic characteristics are reported in Table 1.

About half of the participants reported that they had assisted with five or fewer women experiencing stillbirths during their career (50.8\%), one quarter $(23.8 \%)$ had assisted with 5-10 stillbirths, and one fifth (19.1\%) had assisted with more than 10 stillbirths. Only $6.3 \%$ had never assisted at the birth of a stillborn baby.

Table 2 summarises cognition, emotions and behaviours of professionals when dealing with stillbirth. The most commonly reported feelings were emotional involvement $(90.3 \%)$ and pain $(82.8 \%)$. Communicating the news of the death was recognized as the greatest emotional
Table 1

Demographic characteristics of participants.

\begin{tabular}{ll}
\hline GenderGender & $N(\%)$ \\
\hline Female & $633(94.1 \%)$ \\
Male & $40(5.9 \%)$ \\
Profession & $N$ \\
\hline Midwives & $491(72.8 \%)$ \\
Physicians & $99(14.70 \%)$ \\
Nurses & $43(6.40 \%)$ \\
Others & $41(6.10 \%)$ \\
Age & Mean (SD) \\
\hline All respondents & $37.6(10.4)$ \\
Nurses & $42.6(7.54)$ \\
Physicians & $40.6(10.94)$ \\
Midwives & $37.3(10.59)$ \\
Others & $28.1(9.46)$ \\
Years of work experience & Mean (SD) \\
\hline All respondents & $13.7(10.79)$ \\
Nurses & $19.0(9.12)$ \\
Midwives & $14.3(11.2)$ \\
Physicians & $11.7(10.87)$ \\
Others & $4.7(6.19)$ \\
\hline
\end{tabular}

challenge (79.4\%), followed by caring for the baby (69.0\%) and supporting parents in the postpartum phase (62.2\%).

Table 3 presents the most common attitudes of Italian HCPs towards parents and their stillborn babies. While some care practices recommended by international guidelines are widespread, other common approaches are absent. The majority of participants felt that the best ways that HCPs can help parents after a diagnosis of stillbirth included supporting the parents to stay together (97.6\%), explaining what will happen (95.5\%), and providing personalized care (88.0\%). Almost all deemed it useful for the parents in the most critical situation to stay in a peaceful environment (98.5\%), to receive support $(97.1 \%)$ and proper information on what was happening $(95.3 \%)$, and to be listened to empathetically (93.4\%). While the presence of the partner was considered beneficial by most $(92.2 \%)$, only one-quarter $(24.6 \%)$ believed that other relatives should be allowed in the room.

While many good practices related to an interpersonal approach with the mother seem to have been acquired by HCPs, some other issues that are more specific to stillbirth management seem to have been neglected (Table 4). About one half of practitioners $(51.0 \%)$ recommended immediate birth; only $55.0 \%$ routinely bathe and clothed the child before letting the parents see the baby, whereas the other half (44.4\%) usually removed the baby immediately from the parents. With regard to birth options: the most appropriate type of labour and birth for women with an in-utero death was reported as spontaneous labour(91.3\%), with induced labour supported by $76.9 \%$. In response to pain relief questions, the use of analgesia during labour was supported by $90.4 \%$ but almost half $(47.2 \%)$ also mentioned the use of sedation (which is not supported in most guidelines); $7.6 \%$ stated that the preferred birth method was caesarean section.

With regard to coping strategies, HCPs report they actively support the mother during birth (97.6\%). Others coping strategies were offering postnatal care $(95.5 \%)$ and shortening the length of stay after the birth $(82.0 \%)$. Nevertheless, only three-quarters $(76.3 \%)$ reported that it was important for parents to be allowed to stay with their baby for as long as they need, and less than half (41.1\%) thought it was useful to take photos of the stillborn baby as mementos for the parents.

The majority of HCPs stated that during the post-partum period, to provide adequate support to the family, it is helpful to refer the bereaved mother to community - services $(86.7 \%)$ and to organise followup meetings (79.9\%). Just over two-thirds (71.1\%) mentioned raising awareness about the feelings that may arise after the loss, but less than 
Table 2

Cognition, emotions and behaviours of Italian perinatal HCPs with regard to stillbirth care.

\begin{tabular}{lcll}
\hline \multicolumn{4}{l}{ What are HCPs' most common feelings when dealing with stillbirth? } \\
\hline & Yes N (\%) & No N (\%) & Do not know N (\%) \\
\hline Emotional involvement & $586(90.3 \%)$ & $36(5.5 \%)$ & $27(4.2 \%)$ \\
Pain & $526(82.8 \%)$ & $56(8.8 \%)$ & $53(8.3 \%)$ \\
Embarrassment & $218(34.6 \%)$ & $324(51.4 \%)$ & $88(14.0 \%)$ \\
Inadequacy to face the critical situation & $342(54.3 \%)$ & $188(29.8 \%)$ & $100(15.9 \%)$ \\
Failure to provide support to the family & $46(7.5 \%)$ & $474(76.8 \%)$ & $97(15.7 \%)$ \\
& & & \\
What are the greatest emotional challenges for HCPs? & & Do not know N (\%) \\
\hline & Yes N (\%) & No N (\%) \\
& $586(90.3 \%)$ & $36(5.5 \%)$ & $27(4.2 \%)$ \\
\hline Communicating the news of the death & $419(69.0 \%)$ & $76(12.5 \%)$ & $112(18.5 \%)$ \\
Encountering the dead child & $409(62.2 \%)$ & $70(10.6 \%)$ & $179(27.2 \%)$ \\
Supporting the parents in the post-partum & $336(61.4 \%)$ & $105(19.2 \%)$ & $106(19.4 \%)$ \\
Providing assistance during the birth & $331(60.3 \%)$ & $109(19.9 \%)$ & $109(19.9 \%)$ \\
Providing assistance during labour & & & \\
\hline
\end{tabular}

Table 3

Attitudes of Italian perinatal HCPs towards parents and stillborn babies.

\begin{tabular}{|c|c|c|c|}
\hline \multicolumn{4}{|l|}{ How can HCPs help parents after a stillbirth? } \\
\hline & Yes $\mathrm{N}(\%)$ & No N (\%) & Do not know N (\%) \\
\hline Allowing the parents to stay together & $649(97.6 \%)$ & $9(1.4 \%)$ & $7(1.1 \%)$ \\
\hline Explaining what will follow & $634(95.5 \%)$ & $15(2.3 \%)$ & $15(2.3 \%)$ \\
\hline Providing personalized care & $565(88.0 \%)$ & $37(5.8 \%)$ & $40(6.2 \%)$ \\
\hline Recommending immediate birth & $328(51.0 \%)$ & $84(13.1 \%)$ & $231(35.9 \%)$ \\
\hline Bathing and settling the child before allowing parents to see the baby for as long as they need & $340(55.0 \%)$ & $154(24.9 \%)$ & $124(20.1 \%)$ \\
\hline Immediately taking the child away from the parents & $272(44.4 \%)$ & $234(38.2 \%)$ & $106(17.3 \%)$ \\
\hline Staying in a peaceful environment & $645(98.5 \%)$ & $4(0.6 \%)$ & $6(0.9 \%)$ \\
\hline Receiving support & $633(97.1 \%)$ & $9(1.4 \%)$ & $10(1.5 \%)$ \\
\hline Receiving proper information on what is happening & $623(95.3 \%)$ & $8(1.2 \%)$ & $23(3.5 \%)$ \\
\hline Listening empathetically & $607(93.4 \%)$ & $16(2.5 \%)$ & $27(4.2 \%)$ \\
\hline Presence of the partner & $603(92.2 \%)$ & $25(3.8 \%)$ & $26(4.0 \%)$ \\
\hline Presence of relatives & $155(24.6 \%)$ & $194(30.8 \%)$ & $281(44.6 \%)$ \\
\hline
\end{tabular}

Table 4

Practices and strategies of Italian perinatal HCPs when dealing with stillbirth.

\begin{tabular}{|c|c|c|c|c|}
\hline \multicolumn{5}{|c|}{ Which is the most suitable type of delivery in case of stillbirth? } \\
\hline & Yes N (\%) & \multicolumn{2}{|l|}{ No $\mathrm{N}(\%)$} & Do not know N (\%) \\
\hline Spontaneous labour & $515(91.3 \%)$ & \multicolumn{2}{|l|}{$23(4.1 \%)$} & $26(4.6 \%)$ \\
\hline Induced labour & $422(76.9 \%)$ & \multicolumn{2}{|l|}{59 (10.7\%) } & $68(12.4 \%)$ \\
\hline Caesarean section & $40(7.6 \%)$ & \multicolumn{2}{|l|}{$335(63.4 \%)$} & $153(29.0 \%)$ \\
\hline Use of analgesia during labour & $519(90.4 \%)$ & \multicolumn{2}{|l|}{$25(4.4 \%)$} & $30(5.2 \%)$ \\
\hline Use of sedatives during labour & $291(47.2 \%)$ & \multicolumn{2}{|l|}{$174(28.2 \%)$} & $152(24.6 \%)$ \\
\hline \multicolumn{5}{|c|}{ What are the best strategies to help parents cope with grief and loss? } \\
\hline & Yes N (\%) & \multicolumn{2}{|c|}{ No $\mathrm{N}(\%)$} & Do not know N (\%) \\
\hline Supporting mothers during the birth & $648(97.6 \%)$ & \multicolumn{2}{|c|}{$9(1.4 \%)$} & $7(1.1 \%)$ \\
\hline Offering postnatal care & $632(95.5 \%)$ & \multicolumn{2}{|c|}{$14(2.1 \%)$} & $16(2.4 \%)$ \\
\hline Shortening the length of stay & $533(82.0 \%)$ & \multicolumn{2}{|c|}{$46(7.1 \%)$} & $71(10.9 \%)$ \\
\hline Allowing parents to spend time with their baby & $493(76.3 \%)$ & \multicolumn{2}{|c|}{$62(9.6 \%)$} & $91(14.1 \%)$ \\
\hline Taking photos of the stillborn baby as mementos & $260(41.1 \%)$ & \multicolumn{2}{|c|}{$185(29.3 \%)$} & $187(29.6 \%)$ \\
\hline \multicolumn{5}{|c|}{ What are the best ways that HCPs can offer adequate support to the family in the post-partum? } \\
\hline & & Yes N (\%) & No N (\%) & Do not know N (\%) \\
\hline \multicolumn{2}{|l|}{ Referring the bereaved mother to a counselling centre } & $490(86.7 \%)$ & $26(4.6 \%)$ & $49(8.7 \%)$ \\
\hline \multicolumn{2}{|l|}{ Setting up follow-up meetings } & $466(79.9 \%)$ & $24(4.1 \%)$ & $93(16.0 \%)$ \\
\hline \multicolumn{2}{|c|}{ Raising awareness about the feelings that may arise after the grief experience } & $393(71.1 \%)$ & $66(11.9 \%)$ & $94(17.0 \%)$ \\
\hline \multicolumn{2}{|c|}{ Providing families with informative materials on how to cope with the loss } & $261(47.4 \%)$ & $78(14.2 \%)$ & $212(38.5 \%)$ \\
\hline \multicolumn{2}{|c|}{ Suggesting trying to conceive soon after stillbirth in order to ease the grieving process } & $76(13.1 \%)$ & $194(33.3 \%)$ & $312(53.6 \%)$ \\
\hline
\end{tabular}

half (47.4\%) mentioned providing families with written information on how to cope with the loss. Only one-third recognised that trying to conceive soon after a stillbirth was not advisable with $13.1 \%$ reporting that it could help parents with the grieving process, whereas more than half (53.6\%) declared they were "unsure".
Only a half of respondents (50.3\%) reported being aware of the existence of self-help groups that offer support to bereaved parents; among those, $83.9 \%$ passed this information onto parents. The need for practice guidelines for HCPs supporting families after a perinatal loss was expressed by $89.4 \%$ of HCPs. Correspondingly, a large majority (90.2\%) 
Table 5

Number of Italian perinatal HCPs complying with international guidelines in each section.

\begin{tabular}{|c|c|c|}
\hline \multirow[t]{2}{*}{ Sections } & \multicolumn{2}{|c|}{ Italian HCPs aware of guidelines recommendation N/TOT (\%) } \\
\hline & Aware of all items & Aware of at least $80 \%$ items \\
\hline $\begin{array}{l}\text { Respect for baby and parents (i.e. naming the baby, bathing and dressing the baby, providing privacy, } \\
\text { allowing partners to spend time together, etc.) }\end{array}$ & $2 / 674(0.30 \%)$ & $29 / 674(4.32 \%)$ \\
\hline $\begin{array}{l}\text { Birth Options (i.e. offering parents choices, offering the option of returning home, offering obstetric } \\
\text { analgesia, avoiding sedation, etc.) }\end{array}$ & $3 / 674(0.45 \%)$ & $41 / 674(6.10 \%)$ \\
\hline $\begin{array}{l}\text { Creating Memories (i.e. allowing parents to see and hold their baby, providing mementos such as a lock } \\
\text { of hair, footprints, ID bracelet, etc.) }\end{array}$ & $188 / 674(27.89 \%)$ & $363 / 674(54.75 \%)$ \\
\hline $\begin{array}{l}\text { Aftercare (i.e. informing mothers about physical and psychological consequences of perinatal loss, } \\
\text { providing early psychological support, providing written information on support services, discussing } \\
\text { implications for future pregnancies, etc.) }\end{array}$ & $18 / 674(2.67 \%)$ & $337 / 674(50.00 \%)$ \\
\hline
\end{tabular}

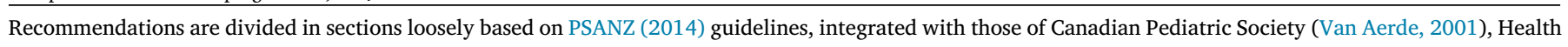
Services Executive Ireland (2016) and WHO-UNFPA-UNICEF (2007).

conveyed their interest in attending professional training courses, and $83.1 \%$ declared that participating in continuing education courses on perinatal loss support could help them improve their daily practice. Attending regular meetings with other HCPs would make three-quarters (79.9\%) change their own approach in such important situations. Although, three-quarters (76.1\%) had never previously attended a professional training course on perinatal loss care.

Finally, Table 5 summarises Italian perinatal HCPs' beliefs on stillbirth, obtained via the Lucina interview, in accordance with the international guideline recommendations in the four chosen areas of the CLASS checklist: Respect, Birth, Mementos and Aftercare. Comparison of the current practice against international guidelines using the CLASS checklist is also presented in Table 5 showing the gaps in practice; in particular, most gaps were present in the sections 'Respect' (i.e. naming the baby, bathing and dressing the baby) and 'Birth' (i.e. offering obstetric analgesia, avoiding sedation).

\section{Discussion}

This is the first study conducted in Italy that investigates HCPs' opinions and behaviours in the care of women and families experiencing stillbirth, examines HCPs' compliance with international guidelines, and explores HCPs' perceived need for specific post-graduate training on perinatal death.

\section{Experiences and feelings regarding stillbirth}

The majority of respondents were midwives with at least one previous experience of caring for women who a stillbirth. Most of them perceived certain situations-particularly communicating the tragic news to the parents and encountering the stillborn baby after birth-as being extremely difficult and felt they were inadequately trained to deal with these events. Although the vast majority (76.8\%) did not feel they fail to provide support to the family, other data do not support this view. Almost all HCPs report pain and emotional involvement; more than onethird said they felt embarrassed and only one-third believed they adequately addressed the situation. These results seem to reveal the lack of awareness of a theoretical framework for grief support, with HCPs' actions based on their personal beliefs and feelings, driven more by sympathy or compassion than by empathy. Both compassion and sympathy are evoked when something negative happens to another person, they imply a desire to help but do not necessarily result in a helpful action (Jeffrey, 2016). Empathy instead can be defined as the ability to identify and understand another person's feelings and perspective from an objective stance (Morse et al., 1992). Empathy is generally regarded as an essential component of the HCP-patient relationship, is linked to lower levels of burn-out (Larson and Yao, 2005), improved patient satisfaction (Derksen et al., 2013) and better clinical outcomes (Mercer et al., 2008). In contrast to sympathy and compassion, empathy is a learned construct (Stansfield et al., 2016), therefore the lack of specific training in bereavement care may hamper HCPs' capabilities of providing useful support to parents. Many of the HCPs reported feeling confused and unable to discuss their common feelings or emotional challenges when working with parents after stillbirth (Table 2 'do not know' column). They reported feeling 'pain' and 'involvement', which is classically considered a sympathetic and not empathetic approach.

In countries such as the United Kingdom (UK), Ireland, Canada and Australia, evidence-based guidelines targeting all HCPs involved are available. These guidelines recognise that good preparation regarding psychological aspects of mourning and grief is useful for HCPs to properly manage situations of high emotional impact and to support bereaved parents. The availability of information materials on perinatal grief has been shown to be relevant for both HCPs and parents (Capitulo, 2004; Flenady et al., 2014; Geller et al., 2006). Moreover, after perinatal loss, many women report how important it is to receive the support of trained staff who are capable of empathic communication and psychological support (Gold, 2007; Heazell et al., 2016). Parents value the kindness as well as professional expertise, and tend to think highly of HCPs who sensitively recognise the painful importance of this loss for parents and who show respect for their baby, e.g. by performing simple tasks such as, using the baby's name, holding the baby you would hold a live baby, and bathing and dressing the baby with compassionate care (Downe et al., 2013). Regrettably, the findings of our study seem to indicate that offering empathetic support is very difficult for care providers in Italy, and that they are seldom taught how to provide personalised assistance, empathic listening, and appropriate information and suggestions when working with families experiencing stillbirth.

Only a very small percentage of the sample was represented by psychologists. Although the absence of psychologists or other figures trained in loss and grief management has been shown to have a negative impact on other staff members who are simply left alone during traumatic events (Gold et al., 2007; Wallbank and Robertson, 2013). Unfortunately, most obstetric units in Italian hospitals are still lacking trained psychologists able to work with both the families and care providers when traumatic events occur.

\section{Compliance with international guidelines}

According to international guidelines, specific training plays an important role in promoting compassionate and supportive assistance both after the diagnosis of stillbirth and after the birth itself. Evidencebased guidelines suggest that the sensitive management of the "first and last" meetings with the baby are particularly important. Care providers should prepare parents for the birth of their baby and should be able to adequately explain what to expect during birth. A gentle approach with parents during labour, after birth, and also with the baby eases parents to meeting the baby (Kavanaugh and Moro, 2006); parents should be enabled to see their baby for as long as they wish. The professionals' attitude towards the stillborn baby could considerably effect the parents' choice to see and hold the baby; parents should always be put in a po- 
sition to choose what to do. Bereaved parents consider it important to be free in expressing their thoughts, their emotions and building memories (Bonanno and Kaltman, 2001; Côté-Arsenault and Denney-Koelsch, 2011), and in the length of time they are able to hold the child (Sanchez, 2001).

Regrettably, a considerable proportion of HCPs in our study seem unsure of the recommended best practices after a perinatal death. The most widespread poor or non-evidence-based practices include recommending immediate birth (51\%), immediately removing the baby from the parents (44\%), and not enabling parents to bathe and dress or hold the baby (45\%). Moreover, while it has been shown that taking nice pictures of the deceased child can be helpful for parents' grieving process, especially when they were doubtful or unable to see the baby (Blood and Cacciatore, 2014; Klass, 2006), only $41 \%$ of HCPs who participated in our study felt that photos of the stillborn baby would be useful as mementos for parents, and one-third stated that this was not an example of good practice. Less than half of respondents provide families with informative materials and only a third are fully aware that trying to conceive soon after stillbirth is not an effective strategy to cope with the loss.

These are basic procedures recommended by all international guidelines which seem to be ignored by a number of Italian HCPs possibly because they have never received appropriate training in this area. The findings from our study highlight that awareness of stillbirth guidelines is presently insufficient. In particular, when Italian HCPs' practices are systematically evaluated by means of the CLASS instrument, we note that full knowledge of all recommended practices is extremely low in all sections, with Respect, Birth Options and Aftercare scoring below 3\% and Memories only scoring $28 \%$. When a lower threshold is applied, still only $55 \%$ of HCPs were able to recognise at least $80 \%$ of recommendations in the Memory section, $50 \%$ of them in Aftercare section, and only $4 \%$ and $6 \%$ in Respect and Birth Options sections, respectively. These inappropriate behaviours may be due to a lack of specific pre-service and inservice for medical staff and midwives, but are probably also maintained by the lack of auditing and undertaking debriefing meetings for perinatal care with regard to perinatal loss support and management (van Diem et al., 2012).

\section{Need for training}

Our study highlights that pre-service and in-service training courses on perinatal loss for HCPs are strongly needed and openly requested. Italian professionals expressed the need to be trained in bereavement care. Specific courses may also be useful to improve HCPs' behavioural techniques and communication skills. The care that parents receive after the birth of a stillborn baby has a significant impact on their perception and memories of what happened, on their ability to cope in the present and in the future, and with important consequences for their long-term well-being. Good care cannot repair the loss and grief that parents feel, however an insensitive care and non-evidence-based approach can make things worse. There is much that professionals can do to ensure that the memories parents take away with them are as positive as possible (Henley and Schott, 2008).

More than three-quarters of our respondents have never received any specific training on the care of women experiencing stillbirth or bereavement support. Despite most of having extensive work experience (mean 13.7 years); consistently, almost all of them showed interest in such courses. It should be noted that the Italian healthcare system and Italian universities are almost completely lacking in expert and trained personnel to address this practice gap with the international community. The few training courses available are organized by parent and professional organizations.

\section{Conclusion}

This research has identified a substantial gap in the provision of evidence-based practice provided to women and families experiencing stillbirth. Italian professionals need to improve their ability to provide professional support to families, show respect for the baby, and help parents to cope with the awful reality, for example by properly allowing them to say goodbye to the baby and keep mementoes, such as photos and videos. The implications of this lack of acquaintance with the recommended best practices definitely represent a sub-optimal care for families who experience a perinatal loss.

Our findings could serve as an impetus for healthcare authorities to implement effective policies and to formulate clear and appropriate guidelines targeted to specific professional groups. Moreover, the management of stillbirth and perinatal loss should be a structured part of professional courses in medical and midwifery curricula so that the new generations of doctors and midwives can substantially improve the quality of care for Italian families who experience stillbirth.

\section{Acknowledgements}

The authors would like to thank all professionals involved in the study and the students from several Italian Universities who participated in data recruitment, as well as their tutors. Among them, we would particularly like to thank Paola Barzano, Giusy Gallea, Simona Minniti, Mara Onorari, Gloria Pelagalli, Simona Peraldi, Serena Serlupi D’Ongran, Solidea Spigato, Ester Tatini and Federica Zatti.

The authors would like to thank the external reviewers, Rachel Smith and Deborah Fox (who were anonymous at the time of review) for their extensive comments and suggestions to improve the English language expression of this version of the paper. Thank you also to Lori Hetherington for extensive assistance in editing. We also thank previous anonymous reviewers for their assistance in improving this version.

\section{Conflict of interest}

The authors have no competing interest to declare.

\section{Ethical approval}

The realization of the study was authorized by all participating hospital authorities. All data were acquired and analysed anonymously.

\section{Funding sources}

CiaoLapo Charity for Stillbirth and Perinatal Grief Support provided infrastructure and funding for the realization of the study (documents, material, software, web platforms etc). No researcher received grants, salary or reimbursements.

\section{Clinical trial registry and registration number}

Not applicable.

\section{Supplementary materials}

Supplementary material associated with this article can be found, in the online version, at doi:10.1016/j.midw.2018.05.008.

\section{References}

Blood, C., Cacciatore, J., 2014. Best practice in bereavement photography after perinatal death: qualitative analysis with 104 parents. BMC Psychology 2, 15. doi:10.1186/2050-7283-2-15.

Bonanno, G.A., Kaltman, S., 2001. The varieties of grief experience. Clinical Psychology Review 21, 705-734.

Capitulo, K.L., 2004. Perinatal grief online. MCN. American Journal of Maternal Child Nursing 29, 305-311.

Côté-Arsenault, D., Denney-Koelsch, E., 2011. "My baby is a person”: parents' experiences with life-threatening fetal diagnosis. Journal of Palliative Medicine 14, 1302-1308. doi:10.1089/jpm.2011.0165.

Derksen, F., Bensing, J., Lagro-Janssen, A., 2013. Effectiveness of empathy in general practice: a systematic review. British Journal of General Practice doi:10.3399/bjgp13X660814. 
Downe, S., Schmidt, E., Kingdon, C., Heazell, A.E.P., 2013. Bereaved parents' experience of stillbirth in UK hospitals: a qualitative interview study. BMJ Open 3, e002237. doi:10.1136/bmjopen-2012-002237.

Ellis, A., Chebsey, C., Storey, C., et al., 2016. Systematic review to understand and improve care after stillbirth: a review of parents' and healthcare professionals' experiences. BMC Pregnancy Childbirth 16, 16. doi:10.1186/s12884-016-0806-2.

Ewton, D.S., 1993. A perinatal loss follow-up guide for primary care. Nurse Practitioners 18, 30-32 35-6.

Flenady, V., Boyle, F., Koopmans, L., Wilson, T., Stones, W., Cacciatore, J., 2014. Meeting the needs of parents after a stillbirth or neonatal death. BJOG: An International Journal of Obstetrics \& Gynaecology doi:10.1111/1471-0528.13009.

Flenady, V., Wojcieszek, A.M., Middleton, P., et al., 2016. Stillbirths: Recall to action in high-income countries. Lancet 387, 691-702. doi:10.1016/S0140-6736(15)01020-X.

Frøen, J.F., Cacciatore, J., McClure, E.M., et al., 2011. Stillbirths: why they matter. Lancet 377, 1353-1366. doi:10.1016/S0140-6736(10)62232-5.

Frøen, J.F., Friberg, I.K., Lawn, J.E., et al., 2016. Stillbirths: progress and unfinished business. Lancet 387, 574-586. doi:10.1016/S0140-6736(15)00818-1.

Geller, P.A., Psaros, C., Kerns, D., 2006. Web-based resources for health care providers and women following pregnancy loss. Journal of Obstetric, Gynecologic, and Neonatal Nursing 35, 523-532. doi:10.1111/j.1552-6909.2006.00065.x.

Gold, K.J., 2007. Navigating care after a baby dies: a systematic review of parent experiences with health providers. Journal of Perinatology 27, 230-237. doi:10.1038/sj.jp.7211676.

Gold, K.J., Dalton, V.K., Schwenk, T.L., 2007. Hospital care for parents after perinatal death. Obstetrics \& Gynecology 109, 1156-1166. doi:10.1097/01.AOG.0000259317.55726.df.

Health Services Executive Ireland Bereavement Care Standards Development Group, 2016. National Standards for Bereavement Care following Pregnancy Loss and Perinatal Death. Health Services Executive Ireland (publisher), Dublin (UK) https://www.hse.ie/eng/services/list/3/maternity/bereavement-care/.

Heazell, A.E.P., Siassakos, D., Blencowe, H., et al., 2016. Stillbirths: Economic and psychosocial consequences. Lancet 387, 604-616. doi:10.1016/S0140-6736(15)00836-3.

Henley, A., Schott, J., 2008. The death of a baby before, during or shortly after birth: good practice from the parents' perspective. Seminars in Fetal and Neonatal Medicine 13, 325-328. doi:10.1016/j.siny.2008.03.003.

Homer, C.S.E., Malata, A., Ten Hoope-Bender, P., 2016. Supporting women, families, and care providers after stillbirths. Lancet 387, 516-517. doi:10.1016/S0140-6736(15)01278-7.

Hutti, M.H., 2005. Social and professional support needs of families after perinatal loss. Journal of Obstetric, Gynecologic, and Neonatal Nursing 34, 630-638. doi:10.1177/0884217505279998.

Hutti, M.H., Armstrong, D.S., Myers, J.A., Hall, L.A., 2015. Grief intensity, psychological well-being, and the intimate partner relationship in the subsequent pregnancy after a perinatal loss. Journal of Obstetric, Gynecologic, and Neonatal Nursing 44, 42-50.

Jeffrey, D., 2016. Empathy, sympathy and compassion in healthcare: Is there a problem? Is there a difference? Does it matter? Journal of the Royal Society of Medicine 109, 446-452. doi:10.1177/0141076816680120.

Kavanaugh, K., Moro, T., 2006. Supporting parents after stillbirth or newborn death: there is much that nurses can do. American Journal of Nursing 06, 74-79.

Kersting, A., Wagner, B., 2012. Complicated grief after perinatal loss. Dialogues in Clinical Neuroscience 14, 187-194.

Klass, D., 2006. Continuing conversation about continuing bonds. Death Studies 30, 843 858. doi:10.1080/07481180600886959.
Larson, E.B., Yao, X., 2005. Clinical empathy as emotional labor in the patient-physician relationship. Journal of the American Medical Association doi:10.1001/jama.293.9.1100.

Mercer, S.W., Neumann, M., Wirtz, M., Fitzpatrick, B., Vojt, G., 2008. General practitioner empathy, patient enablement, and patient-reported outcomes in primary care in an area of high socio-economic deprivation in Scotland - a pilot prospective study using structural equation modeling. Patient Education and Counseling 73, 240-245. doi:10.1016/j.pec.2008.07.022.

Morse, J.M., Anderson, G., Bottorff, J.L., et al., 1992. Exploring empathy: a conceptual fit for nursing practice? Image: the Journal of Nursing Scholarship 24, 273-280. doi:10.1111/j.1547-5069.1992.tb00733.x.

Nuzum, D., Meaney, S., O'Donoghue, K., 2014. The impact of stillbirth on consultant obstetrician gynaecologists: a qualitative study. BJOG: An International Journal of Obstetrics \& Gynaecology 121, 1020-1028. doi:10.1111/1471-0528.12695.

PSANZ, 2014. Clinical Practice Guideline for Care Around Stillbirth and Neonatal Death. Perinatal Society of Australia and New Zealand (publisher), Brisbane (AU) https://sanda.psanz.com.au/clinical-practice/clinical-guidelines/.

Pullen, S., Golden, M.A., Cacciatore, J., 2012. "I'll never forget those cold words as long as I live": parent perceptions of death notification for stillbirth. Journal of Social Work in End-Of-Life \& Palliative Care 8, 339-355. doi:10.1080/15524256.2012.732022.

Rådestad, I., Nordin, C., Steineck, G., Sjögren, B., 1998. A comparison of women's memories of care during pregnancy, labour and delivery after stillbirth or live birth. Midwifery $14,111-117$.

Ryninks, K., Roberts-Collins, C., McKenzie-McHarg, K., Horsch, A., 2014. Mothers' experience of their contact with their stillborn infant: an interpretative phenomenological analysis. BMC Pregnancy Childbirth 14, 203. doi:10.1186/1471-2393-14-203.

Säflund, K., Sjögren, B., Wredling, R., 2004. The role of caregivers after a stillbirth: views and experiences of parents. Birth 31, 132-137. doi:10.1111/j.0730-7659.2004.00291.x.

Sanchez, N.A., 2001. Mothers' perceptions of benefits of perinatal loss support offered at a major university hospital. Journal of Perinatal Education 10, 23-30. doi:10.1624/105812401X88165.

SANDS, 2016. Pregnancy Loss and the Death of a Baby: Guidelines for Professionals, forth edn Midwives, London (13558404).

Stansfield, R.B., Schwartz, A., O’Brien, C.L., Dekhtyar, M., Dunham, L., Quirk, M., 2016. Development of a metacognitive effort construct of empathy during clinical training: a longitudinal study of the factor structure of the Jefferson scale of empathy. Advances in Health Sciences Education 21, 5-17. doi:10.1007/s10459-015-9605-1.

UNICEF, WHO, UNFPA, 2017. Managing Complications in Pregnancy and Childbirth 2nd Ed. World Health Organization (publisher), Geneve (CH) http://www.who.int/ maternal_child_adolescent/documents/managing-complications-pregnancychildbirth/en/.

Van Aerde, J., 2001. Guidelines for health care professionals supporting families experiencing a perinatal loss. Paediatrics \& Child Health 6, 469-490.

van Diem, M.T., Timmer, A., Bergman, K.A., et al., 2012. The implementation of unit-based perinatal mortality audit in perinatal cooperation units in the northern region of the Netherlands. BMC Health Services Research 12, 195. doi:10.1186/1472-6963-12-195.

Wallbank, S., Robertson, N., 2013. Predictors of staff distress in response to professionally experienced miscarriage, stillbirth and neonatal loss: A questionnaire survey. The International Journal of Nursing Studies 50, 1090-1097. doi:10.1016/j.ijnurstu.2012.11.022.

Wojcieszek, A., Boyle, F., Belizán, J., et al., 2016. Care in subsequent pregnancies following stillbirth: an international survey of parents. BJOG: An International Journal of Obstetrics \& Gynaecology doi:10.1111/1471-0528.14424. 